\title{
Research on Crotch Structure of Fitted Man's Trousers Based on 3D Scanning Data of Human Body
}

\author{
Zhongqian Guo and Minghai Cui ${ }^{*}$ \\ Beijing Institute of Fashion Technology, Yinghuadongjie, Beijing, 100029, China \\ ${ }^{*}$ Corresponding author
}

\begin{abstract}
It's very crucial for men to have a fit trousers since wearing it is an only option in their daily life. Fit trousers represent comfort and aesthetics. As an essential part of structure in trousers, crotch has deeply influence on the fitness of trousers. This paper focus on the crotch shape of male's trousers based on 3D scanning data. The main contents as follows: To obtain male's body data and crotch curved data by $3 \mathrm{D}$ scanning experiment; To simulate the reality fitting effect on virtual fitting software and to make fitted trousers for every experimenter on it; To contrast 3D scanning crotch curved data and fitted-trousers paper matrix and to sum up the relationship between them. Having got the relationship between $3 \mathrm{D}$ scanning human data and fitting pattern from analyzing the contrasts of them.
\end{abstract}

Keywords-3D scanning; crotch; trousers; virtual fitting; paper matrix

\section{INTRODUCTION}

Trousers are nearly the only choice for men's lower body in their daily life. Whether the fitness of men's trousers or not directly related to the wearing comfort and aesthetics, as one of the most important part of the structure, the crotch influence the fitness degree of pants.

From the relevant literature of the pants structure, although there are a lot of trousers or man's trousers prototype research, especially in this part of the crotch: study of the length of the crotch, front and rear length and it's proportion, the total length of the crotch. but the literature of the relationship between the crotch form and the trousers fit form is very few.

In this paper, it focus on the relationship between the shape of the crotch of the trousers and the human body. As there is no way to obtain the data of human body shape by traditional manual measurement, the part of human body data acquisition adopts 3D anthropometric measurements.

\section{Human BODY THREE-DimENSIONAL SCANNING EXPERIMENT}

The subjects of the experiment were 10 male university students with quality index number of 21-23, height of $175 \pm$ $2.5 \mathrm{~cm}$, weight of $66 \pm 2.5 \mathrm{~kg}$.

3D data scan acquisition was used by Artec Eva 3D scanner Volunteers were required to make standing position as regulations, and then scan the three-dimensional data for about 3 minutes. The raw data are post processed as editing, fitting, compositing, texture mapping, data derivation and so on by
Artec Studio 9 3D scanning software. Then the data were imported into the reverse engineering software RapidformXOR3 to repair the data which is not collected on the crotch. According to the marking points and the marking lines on the volunteer, the characteristic data of each part of the human body were extracted by the reverse engineering software, and so as the external contour line along the sides of the body.

\section{ANALYSIS OF EXPERIMENTAL RESULTS}

\section{A. The Theoretical Basis of Analytical Methods}

The structural relationships of the trousers crotch arc and the crotch of the human body, the front of the pants are aligned with the back of the hip line in the figure. due to the existence of the amount of crotch, the corner of the front and back crotch can not meet directly, should be separated. Make the hip position of the human body sagittal contour line align the intersection of the front crotch arc line and hip line, so that the hip line of human body and pattern of pants can be at the same level of position.

In practice, the crotch of the pants need the ironing operation and so on. The ironing operation of the front crotch should be shrinkage which is performed at $7 \sim 8 \mathrm{~cm}$ in the former small crotch, the shrinkage amount is about $0.3 \sim 0.5 \mathrm{~cm}$ On the contrary, the ironing operation of the back crotch should be pull which is performed at the back crotch arc, the pull amount is about $0.8 \sim 1.2 \mathrm{~cm}$.After the ironing process, the capacity of the pants before the crotch increases, and the pants can be more three-dimensional sense. Then extract the middle sagittal section below human waist and the external contour line along the sides of the body, and compare them with the paper matrix of the fit men's trousers. At last, come to a conclusion by the means of measuring and compare these datas on human body and paper matrix.

In human and clothing, the plate and the human body control method will be the various plate and waist circumference of the body below the median sagittal and lateral contour lines together, the distance between the pants before and after the film is $0.85 \mathrm{~cm}$, then it meet the range of ironing.

\section{B. Analysis of Control Parts by the Crotch Arc Line}

The data need to be measured on the prototype of pants:(1)the length of croth, (2)the length between the hip line and croth, (3) the width of the front crotch; (4) the width of the 
back crotch; (5) the tilt angle for the back crotch: draw the verticle line at the intersection of the back hip line and crotch line, the angle between the verticle line and crotch line is the tilt angle.

The data need to be measured on the human body:(1)the length between the waist line and CR,(2)the length between the hip line and CR,(3)the tilt angle of the human hip: draw the vertile line on the hip of the profile of human body, connect point A and the hip point, the angle between the lines is the tilt angle, (4) the width of front crotch; (5) the width of back crotch: BD.

TABLE I. STATISTICS OF CROTCH CURVE OF HUMAN BODY AND CROTCH (UNIT: MM)

\begin{tabular}{|c|c|c|c|c|c|c|c|c|c|c|}
\hline No. & $\begin{array}{c}\mathbf{M} \sim \mathbf{F} \\
\mathbf{9}\end{array}$ & $\begin{array}{c}\mathbf{M} \sim \mathbf{F} \\
\mathbf{8}\end{array}$ & $\begin{array}{c}\mathbf{M} \sim \mathbf{F} \\
7\end{array}$ & $\begin{array}{c}\mathbf{M} \sim \mathrm{F} \\
\mathbf{6}\end{array}$ & $\begin{array}{c}\mathbf{M} \sim \mathbf{F} \\
5\end{array}$ & $\begin{array}{c}\mathrm{M} \sim \mathrm{F} \\
\mathbf{4}\end{array}$ & $\begin{array}{c}\mathbf{M} \sim \mathbf{F} \\
\mathbf{3}\end{array}$ & $\begin{array}{c}\mathbf{M} \sim \mathbf{F} \\
2\end{array}$ & $\begin{array}{c}\mathbf{M} \sim \mathbf{F} \\
\mathbf{1}\end{array}$ & $\begin{array}{c}\mathbf{M} \sim \mathbf{F} \\
\mathbf{0}\end{array}$ \\
\hline 1 & 9.52 & 9.52 & 9.57 & 9.59 & 9.50 & 9.28 & 8.98 & p & 9.07 & 8.95 \\
\hline 2 & 7.26 & 7.21 & 7.25 & 7.31 & 7.34 & 7.28 & 7.15 & 6.97 & 7 & 7.84 \\
\hline 3 & 10.45 & 10.36 & 10.32 & 10.25 & 10.05 & \begin{tabular}{|l|l|}
9.71 \\
\end{tabular} & 9.29 & 1 & 9.51 & 9.31 \\
\hline 4 & 6.44 & 6.39 & 6.45 & 6.59 & 6.80 & 7.08 & 7.41 & 7.79 & 8.25 & \\
\hline 5 & 7.78 & 7.80 & 7.93 & 8.13 & 8.36 & 8.57 & 8.73 & 8.86 & 1 & 9.42 \\
\hline 6 & 6.78 & 6.77 & 6.86 & 7.01 & 7.18 & 7.30 & 7.37 & 7.38 & 1 & 8.25 \\
\hline 7 & 6.12 & 6.09 & 6.14 & 6.27 & 6.46 & 6.68 & 6.93 & 7.18 & 7.47 & 1 \\
\hline 8 & 4.23 & 4.18 & 4.22 & 4.35 & 4.56 & 4.86 & 5.24 & 5.72 & 6.27 & \begin{tabular}{|l}
6.87 \\
\end{tabular} \\
\hline 9 & 10.38 & 10.28 & 10.18 & 10.01 & 9.75 & 9.41 & / & 9.20 & 8.83 & 8.62 \\
\hline \multirow[t]{2}{*}{10} & 6.95 & \begin{tabular}{|l}
6.77 \\
\end{tabular} & 6.70 & \begin{tabular}{|l|}
6.71 \\
\end{tabular} & 6.80 & 6.96 & 7.18 & 7.47 & 7 & 8.53 \\
\hline & $\begin{array}{l}\mathrm{M} \sim \mathrm{B} \\
1\end{array}$ & $\begin{array}{l}\mathrm{M} \sim \mathrm{B} \\
2\end{array}$ & $\begin{array}{l}\mathrm{M} \sim \mathrm{B} \\
3\end{array}$ & $\begin{array}{l}\mathrm{M} \sim \mathrm{B} \\
4\end{array}$ & $\begin{array}{l}\mathrm{M} \sim \mathrm{B} \\
5\end{array}$ & $\begin{array}{l}\mathrm{M} \sim \mathrm{B} \\
6\end{array}$ & $\begin{array}{l}\mathrm{M} \sim \mathrm{B} \\
7\end{array}$ & $\begin{array}{l}\mathrm{M} \sim \mathrm{B} \\
8\end{array}$ & $\begin{array}{l}\mathrm{M} \sim \mathrm{B} \\
9\end{array}$ & \\
\hline 1 & 8.97 & 9.09 & 9.30 & 9.59 & 9.96 & 10.42 & 10.98 & 11.69 & 12.61 & \\
\hline 2 & 8.11 & 8.53 & 9.09 & 9.76 & 10.51 & 11.29 & 12.11 & 13.01 & 14.06 & \\
\hline 3 & 9.26 & 9.33 & 9.51 & 9.8 & $\mid 10.18$ & 10.69 & 11.34 & 12.18 & 13.25 & \\
\hline 4 & 9.82 & 10.37 & 11.11 & 12.00 & 13.04 & 14.08 & 15.2 & 16.4 & 17.78 & \\
\hline 5 & 9.43 & 9.59 & 9.88 & 10.29 & 10.82 & 11.48 & 12.25 & 13.19 & 14.36 & \\
\hline 6 & 8.40 & \begin{tabular}{|l|} 
\\
\end{tabular} & 9.31 & 9.91 & 10.6 & $\mid 11.37$ & 12.21 & \begin{tabular}{|l|l}
13.17 \\
\end{tabular} & 14.31 & \\
\hline 7 & 8.70 & 9.14 & 9.76 & 10.54 & 11.46 & 12.50 & 13.63 & 14.89 & 16.35 & \\
\hline 8 & / & 8.91 & 9.73 & 10.77 & 11.97 & 13.24 & 14.52 & 15.82 & 17.25 & \\
\hline 9 & 8.52 & 8.54 & 8.65 & 8.85 & 9.15 & 9.55 & 10.10 & 10.81 & 11.75 & \\
\hline 10 & 8.72 & 9.06 & 9.53 & 10.15 & 10.93 & 11.85 & 12.85 & 13.88 & 14.94 & \\
\hline
\end{tabular}

According to the national man type standard GB / T1335.12008 ,the statistical analysis of the volunteer's human body data, it is concluded that the size of these 10 volunteers are 175 / 88Y, 170 / 92Y, 170 / 92A, 175 / 84A, 175 / 92A, 170 / 88Y, 175 / 100A seven different types of body. Comparing the same and differences between the human body curve and the prototype, the following conclusions can be drawn: the fitness on crotch among a variety of different body shapes is related to following two factors, the distance of hip circumference to hip bottom and the width of the middle sagittal section of the crotch horizontaol. Said another way, the distance of hip circumference to hip bottom determines the distance trousers hip circumference to crotch line and the width of the middle sagittal section of the crotch horizontal line determines the total crotch width.

\section{The Analysis of Crotch Arc on Human Body and Fit Trousers}

As the focus is on the analysis of the human body crotch curve and fit the curve of the relationship between the crotch, so compare the relationship between the two hips below the arc is enough. The analysis is done by comparing the distance from the intersection of the vertical line of the SW to the hip line to the curve of the crotch of the human body and the distance of the curve of the crotch of the fitted trousers.

With SW vertical line and hip line intersection as the origin, named $\mathrm{M}$, will be below the hip line of the human body crotch curved line and fit the crotch curved arc in accordance with $10^{\circ}$ interval between the amount of radiation and the crotch of the human body curve and fit the intersection of crotch curved arc. F0, F0 to the left of the f1 f9 and F1 F9, from the f0, F0 to the right for the b1 (F0, F0) to the right of the b1 B9 and B1 $\mathrm{B} 9$, respectively, that the human body, fit the situation before the crotch pants and crotch bending after the situation. Statistics of the statistics of the $M$ to each $F, f$ and $B$, b point distance, analysis and comparison of the same location angle of the line length.

According to the statistical analysis results, you can obtain the compared curves picture of the crotch curve of the volunteers. you can see that two segments of the crotch curve arc at the same angle position are similar, that is to say, fit crotch curved arc and the human body crotch curved arc showed significant similarity, then you can consider that the trousers crotch is fitted when the crotch arcs are similar to each other among trousers and human body.

\section{CONCLUSION}

Due to the lack of research on the crotch part of the male crotch, the research is based on the traditional proportion method, combined with the virtual fitting effect, to produce the fitting pattern of man's trousers.

By contrasting the three-dimensional scanning data and the fitted pattern of man's male trousers, you can come to a conclusion that: the fitness of the crotch of trousers depends on whether the crotch arc of the trousers is similar with the crotch arc of the human body, so that the crotch curve of the fit trousers can be determined by the method of three-dimensional scanning.

The distance of human hip circumference to hip bottom determine the starting point of the crotch curve arc segment; and the width of middle sagittal section of the crotch horizontal determines the total crotch width.

In this paper, the reverse engineering software RapidformXOR3 was used to extract the middle sagittal section and the external contour line along the sides of the body, which was used in the late pattern comparison and data measurement and analysis. 
Development and expectation: The data sample of this subject is fewer, the difference between the volunteers body is big, increase the sample size in the future and count and analysis the regularities of crotch arc line among different shape of human body; and carry through a deep research in garment pattern human body and clothes.

\section{REFERENCES}

[1] Zhi XL. Modified lower body dynamic changes and body pants structure study [D]. Shanghai, Donghua University:2005.

[2] Zhong Ze Yu [Japan], Yuan Guanlu translation. Human body and clothing [M]. China Textile Publishing House:2000.

[3] Zheng Y. Based on tailored female college students body type classification [D]. Xi'an: Xi'an Institute of Engineering Science and Technology:2005.

[4] Yang N, Shen KX.Study on the relationship between the crotch width and the amount of rising of the pants after the combination of the human lower extremity mannequin $[\mathrm{J}]$.International Textile Review:2007;8;76,78-79.

[5] Ellen CM, Elizabeth BKL. Building patternmaking theory: a case study of published patternmaking practices for pants[J]. International Journal of Fashion Design, Technology and Education:2012;5(3);153-167. 